\title{
A vida de um homem de ciência no Antigo Regime português
}

The life of a man of science in the Ancien Régime of Portugal

\author{
Daniela Casoni Moscato \\ Doutoranda, Departamento de História/Universidade Federal do Paraná. \\ historiar7@gmail.com
}

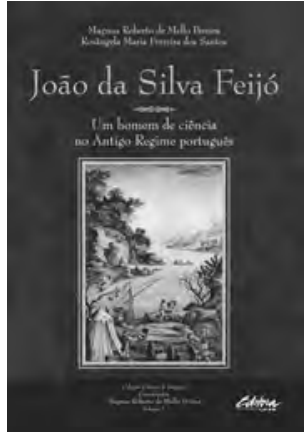

PEREIRA, Magnus Roberto de Mello; SANTOS, Rosângela Maria Ferreira dos. João da Silva Feijó: um homem de ciência no Antigo Regime português. Curitiba: EdUFPR (Coleção Ciência e Império, v.1). 2012. $1046 p$.
Como podemos, como historiadores, narrar a vida de um indivíduo?

O que contaríamos, ou omitiríamos, nos caminhos e descaminhos de uma trajetória humana? Perguntas como essas perseguem os que decidem entrar nessa empreitada historiográfica. Reflexo disso pode ser percebido na contínua produção acadêmica dedicada ao estudo de indivíduos e em "pistas" que cada ensaio, em particular, aponta acerca desse tipo de análise. Essa produção biográfica, democrática e diversificada perpassa por personagens consagrados, como é o caso de Norbert Elias (1995), no estudo Mozart: sociologia de um gênio, e por indivíduos comuns, como o moleiro Domenico Scandella, o Menocchio, indivíduo construído belamente por Carlo Ginzburg (1998). Nessas relações e construções, os autores demonstram particularidades analíticas numa tentativa de apresentar caminhos possíveis, geralmente labirínticos, aos estudos biográficos.

A biografia encontra-se, assim, no centro das preocupações de historiadores, como aponta Giovanni Levi (1998) em seu clássico texto "Usos da biografia". A própria ideia de biografia tornou-se

variada e apresenta, atualmente, alguns gêneros que embasam as análises históricas, tais como "a prosopografia e a biografia modal", que, com base em dados biográficos, objetivam uma prosopografia, descartando, muitas vezes, o interesse pela biografia particular, que, desse modo, apresenta-se como ilustração do comportamento de um determinado grupo, como é o caso da análise realizada em Intelectuais à brasileira, de Sergio Miceli (2001); a "biografia e o contexto", em que o contexto - época, meio e ambiência - caracteriza uma "atmosfera que explicaria a singularidade das trajetórias" (Levi, 1998, p.175); a "biografia e a hermenêutica", gênero mais utilizado pela antropologia interpretativa e pela história oral; e, finalizando, "biografia e casos extremos", cujo exemplo principal é o já citado trabalho de Carlo Ginzburg. Esse gênero, geralmente, alcança o contexto histórico pelas "margens" do campo social, identificadas nas biografias de personagens singulares. Diante de tais variações biográficas e da leitura aprofundada da obra João da Silva Feijó: um homem de ciência no Antigo 
Regime português, pode-se afirmar que tal estudo não se define por uma dessas categorias. Ademais, não se atrela, meramente, à trajetória de João da Silva Feijó (1760-1824).

É importante esclarecer que a narrativa do naturalista João da Silva Feijó é o primeiro volume da Coleção Ciência e Império, um empreendimento nada modesto que tem como objetivo principal apresentar determinados personagens luso-brasileiros, bem como toda sua produção textual. Essa tarefa hercúlea é apoiada pelo Centro de Documentação e Pesquisa de História dos Domínios Portugueses, alocado no Departamento de História da Universidade Federal do Paraná. Essa incursão biográfica não se finda em João da Silva Feijó, e o segundo volume, dedicado a Francisco José de Lacerda Almeida, já foi publicado. Em seguida, virão outros nomes, como Luis Antônio de Oliveira Mendes, Elias Alexandre da Silva Correia, Joaquim José Pereira, Antonio Pires da Silva Pontes, Francisco José de Lacerda.

Esse primeiro volume tem 1.062 páginas, organizadas em duas partes. A primeira apresenta a longa trajetória do naturalista luso-brasileiro João da Silva Feijó; a segunda parte é uma compilação de sua produção científica e compreende 188 documentos correspondências, remessas, memórias, textos científicos etc. - investigados em arquivos portugueses e brasileiros.

Pereira inicia sua narrativa respondendo, diretamente, à seguinte questão: "Quem foi João da Silva Feijó?". Um dos raros luso-brasileiros que conseguiram viver, regularmente, da ciência, Feijó cursou filosofia pela Universidade de Coimbra, tal qual alguns brasileiros do Setecentos, e exerceu a profissão de naturalista na África, em Portugal e no Brasil, sempre a serviço do Império português.

Todavia, se nas primeiras páginas a resposta do autor se mostra um tanto didática, não se pode concluir que o mesmo constrói uma biografia clássica, que expressaria, com base na redução de escala focada no sujeito, as dimensões estruturais e a dinâmica social. Parte do texto, intitulada "Uma biografia nada exemplar", é elaborada por meio de análise minuciosa de diferentes representações do naturalista, construídas por outros autores. Portanto, Pereira busca compreender como a figura de João da Silva Feijó se apresentou em outros estudos, entre eles, os da historiografia portuguesa e norte-americana.

Esse caminho metodológico é instigante e permite ao leitor conhecer as várias representações desse sujeito. A primeira delas é um verbete elaborado pelo geógrafo veneziano Adriano Balbi, em 1822, que destaca os manuais organizados por Feijó para o ensino de botânica e zoologia. Nessa exposição, Pereira apresenta fatos distorcidos e dialoga com cada referência identificada, como as de Carl Friedrich Philipp von Martius, de 1837, e as de Miguel Colmeiro, de 1858. O ápice de tal explanação é o momento em que esclarece o leitor sobre como o desconhecimento de partes da documentação, hoje disponíveis, permitiu a elaboração da imagem de um indivíduo pouco exemplar e a identificação de informações básicas distorcidas. Erros acumulados, que se repetiram ao longo do século XIX, talvez expliquem como esse personagem foi, aos poucos, esquecido pela historiografia brasileira.

Com o intuito de aventar tais representações, o autor analisa, minuciosamente, uma rica documentação - memórias científicas, cartas, periódicos, documentação escolar etc. - para esclarecer possíveis erros e amparar outra narrativa da vida desse naturalista. Nessa perspectiva, constrói o indivíduo biografado. Em "Fazendo-se naturalista", destaca o jovem Feijó e seu período como estudante de filosofia natural, na Universidade de Coimbra; o desenvolvimento 
de relações com outros luso-brasileiros no Jardim da Ajuda, em Lisboa; e os estreitos laços estabelecidos com dom Rodrigo de Souza Coutinho, o conde de Linhares. Esses elementos são o pano de fundo para a análise de sua formação em história natural e da posição ocupada nessa sociabilidade científica, que era composta por nomes como Domingos Vandelli e Alexandre Rodrigues Ferreira.

Em "Um naturalista num ninho de cobras", descreve os anos vividos em Cabo Verde, onde Feijó permaneceu entre junho de 1776 e dezembro de 1795. Tal descrição é fundamentada, especialmente, em um relato de viagem composto por um conjunto de cartas destinadas ao então ministro Martinho de Mello e Castro. Em tal documento, intitulado "O itinerário filosófico que contém a relação das ilhas de Cabo Verde disposto pelo método epistolar", Pereira destaca: a descrição da fauna, da flora e dos costumes locais; os problemas enfrentados por seu biografado - como o da falta de uma equipe de apoio em suas pesquisas; e as funções burocráticas que começou a acumular a partir da década de 1790.

"Un certain Feijào" é dedicada ao retorno a Lisboa. Nessa parte, Pereira ressalta os trabalhos acadêmicos referentes à produção de salitre, o trabalho na Ajuda - onde organizou um herbário com as espécies botânicas enviadas do arquipélago africano - e a aproximação de Feijó com a República das Letras, comprovada pela publicação de alguns de seus estudos. Essa condição de "homem de múltiplos instrumentos" gerou grandes críticas, como as do naturalista alemão Herinrich-Friedrich Link. A esse respeito, Pereira pontua elementos importantes para a compreensão dos discursos de exclusão e exaltação presentes na ciência moderna: "Link buscava afirmar a sua superioridade como intelectual fazendo pouco daqueles colegas que pertenciam a ambientes científicos considerados provincianos ou periféricos" (p.76). Por outro lado, por ser considerado "homem de múltiplos instrumentos", Feijó retornou ao Brasil como sargento-mor das milícias da capitania do Ceará.

Em terras brasileiras, recebeu a incumbência de checar as notícias sobre os depósitos de salitre natural, questão que ocupava lugar importante na política científica portuguesa para o Nordeste brasileiro, debate analisado no subtítulo "Um naturalista no Ceará". Por aproximadamente 15 anos, o naturalista permaneceu na capitania e, além da busca ao salitre, recolheu diversos espécimes que foram enviados ao Jardim Botânico, ao Museu da Ajuda e ao Real Jardim Botânico de Berlim. O autor ainda destaca, sempre amparado pela vasta documentação produzida por Feijó e sobre ele, as publicações de textos referentes à sua atuação no Nordeste e o seu uso por viajantes que estiveram no Brasil no século XIX, como Henry Koster, Johann Baptiste von Spix e Carl Friedrich Philipp von Martius, e Wilhelm Ludwig von Eschewege.

Em toda a trajetória do naturalista Feijó, o autor esclarece seu envolvimento com as estruturas científicas, políticas e sociais presentes no Império português; e, sempre que possível e necessário, atenta para a atuação dessa elite naturalista, representada por seu eleito, em tais articulações. Para Pereira, Feijó tinha um "ar de modernidade" e circulava por espaços importantes, como o da maçonaria e o das Repúblicas das Letras. As últimas páginas são dedicadas à compreensão de como ocorreu a colaboração de Feijó no processo de Independência do Brasil, movimento ao qual ele aderiu, destacando-se no Manifesto do Povo do Rio de Janeiro, que pedia a permanência do príncipe dom Pedro I no país, e na reorganização da maçonaria em terras brasileiras. 
João da Silva Feijó, como bem colocou o autor, foi um homem de seu tempo: participou do movimento português das Luzes, estudou os espécimes naturais de três continentes, vivenciou as construções e as mudanças de paradigmas científicos, acompanhou as rupturas do Império lusitano e, consequentemente, os primeiros embates políticos brasileiros. Contudo, apesar de sua presença em momentos importantes da história portuguesa e brasileira, o naturalista João da Silva Feijó foi esquecido, por um certo tempo, pelos estudos historiográficos. A esse respeito, o livro aqui resenhado não é somente uma tentativa de resgaste de sua vida e obra, mas uma importante ferramente para se "resgatar também um fragmento expressivo da memória científica do Grande Império Lusitano com o qual muitos dos 'filósofos' lusobrasileiros haviam sonhado" (p.119).

\section{REFERÊNCIAS}

ELIAS, Norbert.

Mozart: sociologia de um gênio. Rio de Janeiro: Jorge Zahar. 1995.

GINZBURG, Carlo.

O queijo e os vermes: o cotidiano e as ideias de um moleiro perseguido pela Inquisição. São Paulo: Companhia das Letras. 1998.
LEVI, Giovanni.

Usos da biografia. In: Ferreira, Marieta de Moraes; Amado, Janaina (Org.). Usos e abusos da história oral. Rio de Janeiro: FGV Editora. 1998.

MICELI, Sergio.

Intelectuais à brasileira. São Paulo: Companhia das Letras. 2001. 